\title{
The growth of epitaxial uranium oxide observed by micro-Raman spectroscopy
}

N. Caculitan, W. J. Siekhaus

December 19, 2005

Materials Research Society

Boston, MA, United States

November 28, 2005 through December 2, 2005 
This document was prepared as an account of work sponsored by an agency of the United States Government. Neither the United States Government nor the University of California nor any of their employees, makes any warranty, express or implied, or assumes any legal liability or responsibility for the accuracy, completeness, or usefulness of any information, apparatus, product, or process disclosed, or represents that its use would not infringe privately owned rights. Reference herein to any specific commercial product, process, or service by trade name, trademark, manufacturer, or otherwise, does not necessarily constitute or imply its endorsement, recommendation, or favoring by the United States Government or the University of California. The views and opinions of authors expressed herein do not necessarily state or reflect those of the United States Government or the University of California, and shall not be used for advertising or product endorsement purposes. 


\title{
The growth of epitaxial uranium oxide observed by micro-Raman spectroscopy
}

\author{
Niña Caculitan ${ }^{1}$, Wigbert Siekhaus ${ }^{2}$ \\ ${ }^{1}$ Summer student at the Seaborg Institute at the Dep. of Chemistry and Materials \\ Sciences, ${ }^{2}$ Dep. of Chemistry and Materials Sciences to whom inquiries should be \\ addressed, \\ Lawrence Livermore National Laboratory \\ Livermore, CA 94550-9234
}

\begin{abstract}
Raman spectroscopy can be performed with micrometer resolution and can thus be used to determine the dependence of oxide thickness on the substrate's grain structure or local impurity inclusions. The Raman signal amplitude emitted from an epitaxial uranium oxide layer as a function of oxide thickness has been modeled for light of $632.8 \mathrm{~nm}$ wavelength incident on the oxide and reflected from the uranium substrate using the optical properties determined by spectrophotometry. The model shows that the Raman signal increases with oxide thickness and saturates at about $150 \mathrm{~nm}$ thickness. The model was compared with the measured Raman signal amplitude of an epitaxial uranium oxide layer growing in air with a known time dependence of oxide growth.
\end{abstract}

\section{INTRODUCTION}

Micro-Raman spectroscopy has been performed on a variety uranium oxide single crystals $[1,2,3,4]$, and characteristic Raman lines have been identified for stoichiometric, sub- and super-stoichiometric oxides and even ion bombarded oxides. The stoichiometry and impurity composition of the oxide grown in a laboratory atmosphere on a uranium substrate is of interest, because uranium oxide protects to some extent the underlying uranium from corrosive attack by other gases. Of particular interest is the attack by hydrogen, which initiates preferentially at isolated sites [4]. The mechanism of local initiation is not completely understood. One hypothesis [5] suggests that hydrogen attack occurs at a spot where the protective oxide presents the lowest impedance to diffusion of hydrogen. That impedance to diffusion depends on the thickness of the oxide layer, but potentially also on the stoichiometry or the impurity content of the oxide layer. It is therefore of interest to analyze the surface oxide with a tool that can identify with $\mu-m$ spatial resolution both the thickness and the stoichiometry of the oxide where hydride initiation occurs. In this study we observe a growing uranium oxide layer as a function of time with micro-Raman spectroscopy to determine whether the oxide thickness can be determined from the time-dependent integral of the Raman signal over a wavelength range, and compare the results with a model that describes the expected signal strength. Changes in oxide moiety as a function of thickness are also observed. 


\section{EXPERIMENTAL DETAILS}

A uranium sample with a total weight impurity content of approximately $150 \mathrm{ppm}$ was mechanically polished, finishing with $1 \mu \mathrm{m} \mathrm{SiO}_{2}$ particles and exposed to laboratory air, typically having $35 \%$ relative humidity. Raman spectra were collected as a function of time using a commercial micro-Raman spectrometer ( HORIBA Jovin Yvon, Edison, New Jersey, NJ 08820-3012) using a excitation wavelength of $532 \mathrm{~nm}$, and an x50 objective. The grain size of uranium is $>10 \mu \mathrm{m}$, much larger than the spatial the microscope's resolution. All data were taken on the same grain. To eliminate spurious signals, several $1200 \mathrm{~s}$ scans over a wavelength range from 300 to $1350 \mathrm{~cm}^{-1}$ were averaged. Back-ground subtraction and integration of the time-dependent integral of the Raman signal over a wavelength range from 350 to $800 \mathrm{~cm}^{-1}$ was done using the software provided with the micro-Raman spectrometer. Changes in instrumental sensitivity were corrected by using the signal from a silicon wafer with native oxide as calibration standard. The same surface was monitored as a function of time using optical reflectrometry and ellipsometry [1].

\section{DISCUSSION}

A Raman spectrum of an approximately $40 \mathrm{~nm}$ thick uranium oxide layer is shown in figure 1 .

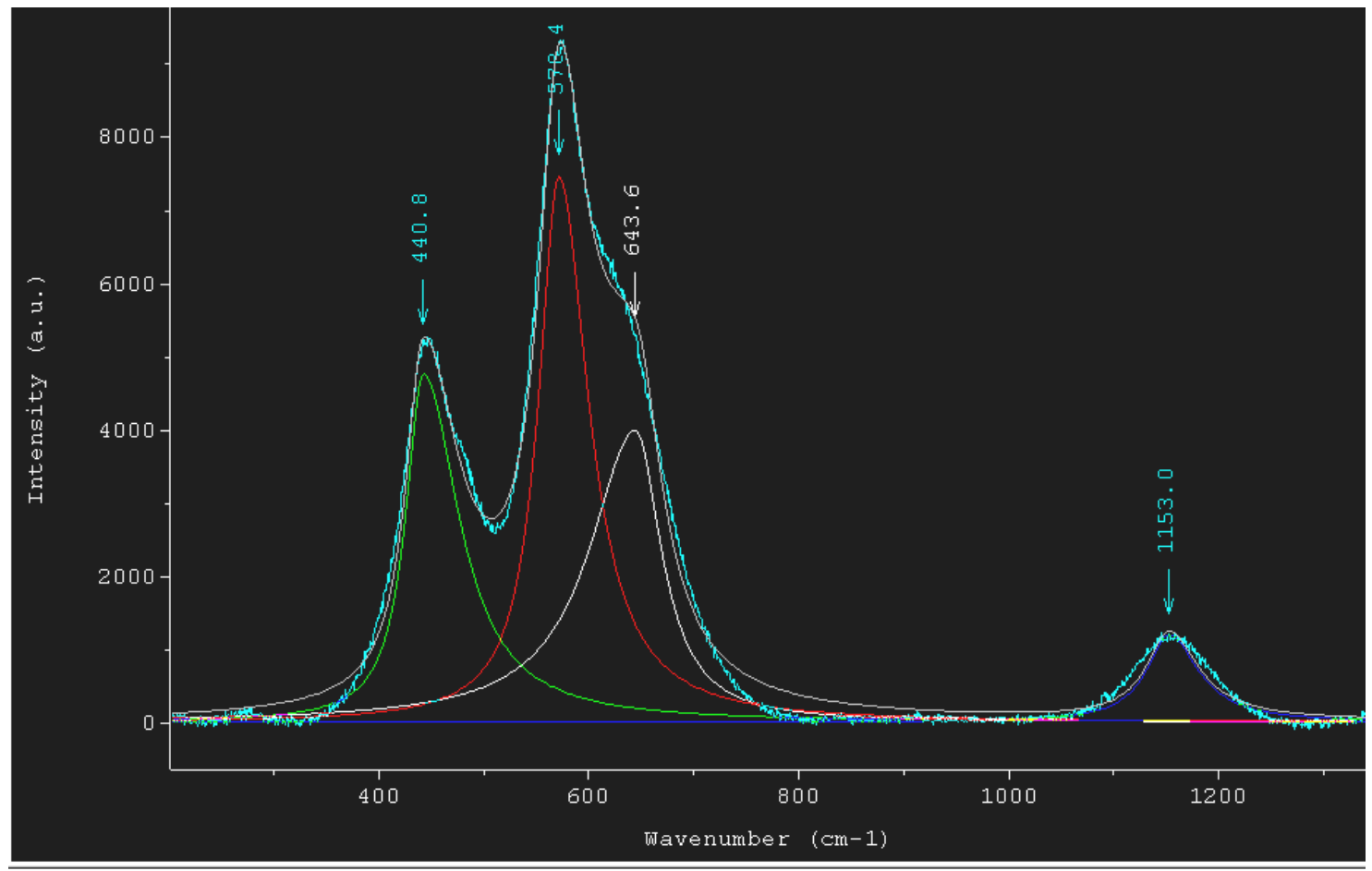

Figure 1. Raman spectrum of uranium oxide on a uranium substrate.

The background has been substracted using a fifth order polynomial, and the instrument's software has been used to fit the observed peaks. To determine the strength of the oxide 
Raman signal as a function of time the spectrum was integrated from 350 to $800 \mathrm{~cm}^{-1}$. Table 1 shows peak values observed in the literature cited in the introduction.

Table 1. Raman peak values observed in the literature cited in the introduction

\begin{tabular}{|l|l|l|l|l|l|l|l|l|l|l|l|l|}
\hline Species & \multicolumn{10}{|c|}{ Literature values, $\mathbf{c m}^{-1}$} \\
\hline$\alpha \mathrm{U}_{3} \mathrm{O}_{8}$ & & 235 & 340 & 410 & & & 475 & & 640 & 750 & 805 & \\
\hline $\mathrm{U}_{4} \mathrm{O}_{9}$ & 210 & & & & & 465 & & & & & & \\
\hline $\mathrm{UO}_{2}$ & & & & & 446 & & & & & & & 1150 \\
\hline $\begin{array}{l}\mathrm{UO}_{2} \mathrm{Kr} \\
\begin{array}{l}\text { ion } \\
\text { bomb. }\end{array}\end{array}$ & & & & & 446 & & & 575 & & & & 1150 \\
\hline $\mathrm{B}_{-} \mathrm{U}_{3} \mathrm{O}_{7}$ & 210 & & & & & 465 & & & & & & \\
\hline
\end{tabular}

It is apparent that the oxide layer consists of a number of moieties, mostly $\mathrm{UO}_{2}$, with a smaller contribution from $\alpha \mathrm{U}_{3} \mathrm{O}_{8}$. There is a small shoulder to the right of the $446 \mathrm{~cm}^{-1}$ where the $465 \mathrm{~cm}^{-1}$ peak of $\mathrm{U}_{4} \mathrm{O}_{9}$ and $\mathrm{B}-\mathrm{U}_{3} \mathrm{O}_{7}$ is located, indicating that these moieties are present in small concentration. There is in addition a strong peak at $\sim 575$ $\mathrm{cm}^{-1}$ that has been seen in $\mathrm{Kr}$ ion bombarded $\mathrm{UO}_{2}$, indicating a damaged $\mathrm{UO}_{2}$ lattice. It is possible a consequence of the large lattice mismatch between the oxide and the substrate.

\section{Model of the expected signal integral as a function of oxide thickness.}

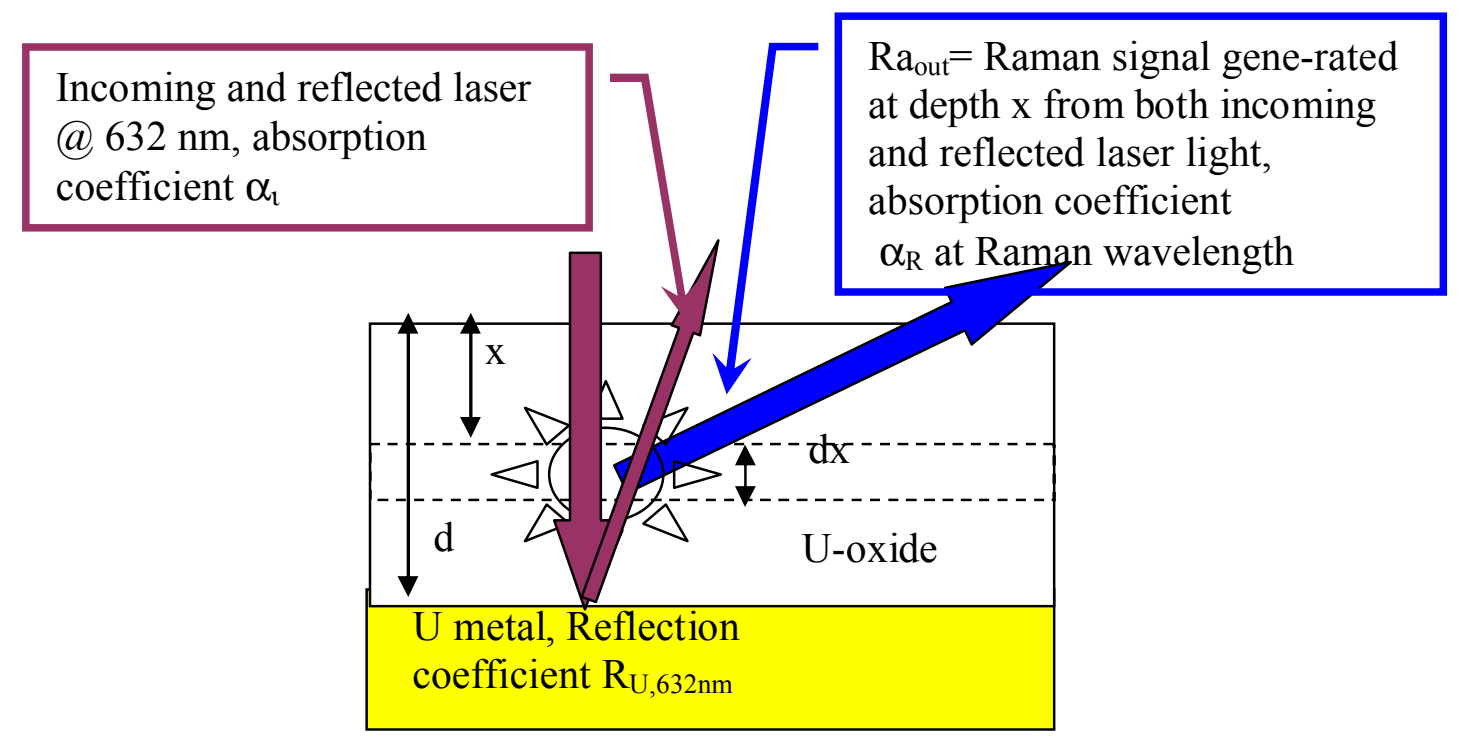

Figure 2. Interaction of the of the incoming laser beam with the uranium substrate and the oxide layer to generate a Raman signal.

The incoming laser beam with a wavelength of $632 \mathrm{~nm}$ excites a Raman signal at each location $\mathrm{x}$ below the surface, is attenuated as it passes through the oxide with an absorption coefficient $\alpha_{1}$ and is reflected by the uranium substrate with a 
reflection coefficient $\mathrm{R}_{\mathrm{U}, 632 \mathrm{~nm}}$. The reflected beam generates an additional Raman signal at each $\mathrm{x}$. The outgoing Raman signal is attenuated by an absorption coefficient $\alpha_{R}$. Integration over the oxide thickness $d$ yields the total outgoing Raman signal $\mathrm{Ra}_{\text {out }}$.

$$
\begin{aligned}
& R a_{\text {out }} \approx \mathrm{I}_{\mathrm{o}} \sigma_{\mathrm{Ra}}\left[\frac{1-e^{-\left(\alpha_{i}+\alpha_{R a}\right) d}}{\alpha_{i}+\alpha_{R a}}+\mathrm{R}_{\mathrm{U}, 632 \mathrm{~nm}} \frac{e^{-2 \alpha_{i} d}\left(-1+e^{\left(\alpha_{i}-\alpha_{R a}\right) d}\right)}{\alpha_{i}-\alpha_{R a}}\right] \\
& \text { If } \alpha_{i}=\alpha_{R a}, R a_{\text {out }} \approx \mathrm{I}_{\mathrm{o}} \sigma_{\mathrm{Ra}}\left[\frac{1-e^{-2 \alpha_{i} d}}{2 \alpha_{i}}+\mathrm{R}_{\mathrm{U}, 632 \mathrm{~nm}} e^{-2 \alpha_{i} d} * d\right]
\end{aligned}
$$

where $\mathrm{I}_{0}$ is the intensity of the incoming laser and $\sigma_{\mathrm{Ra}}$ is the Raman cross section.

\section{Comparison of model and measured values.}

Equation (2) was fit to the observed data, using a reflection coefficient $\mathrm{R}_{\mathrm{U} .632 \mathrm{~nm}}$ of .5 determined by reflectrometry [1]. Figure 3 shows the fit, and the fitting coeffients.

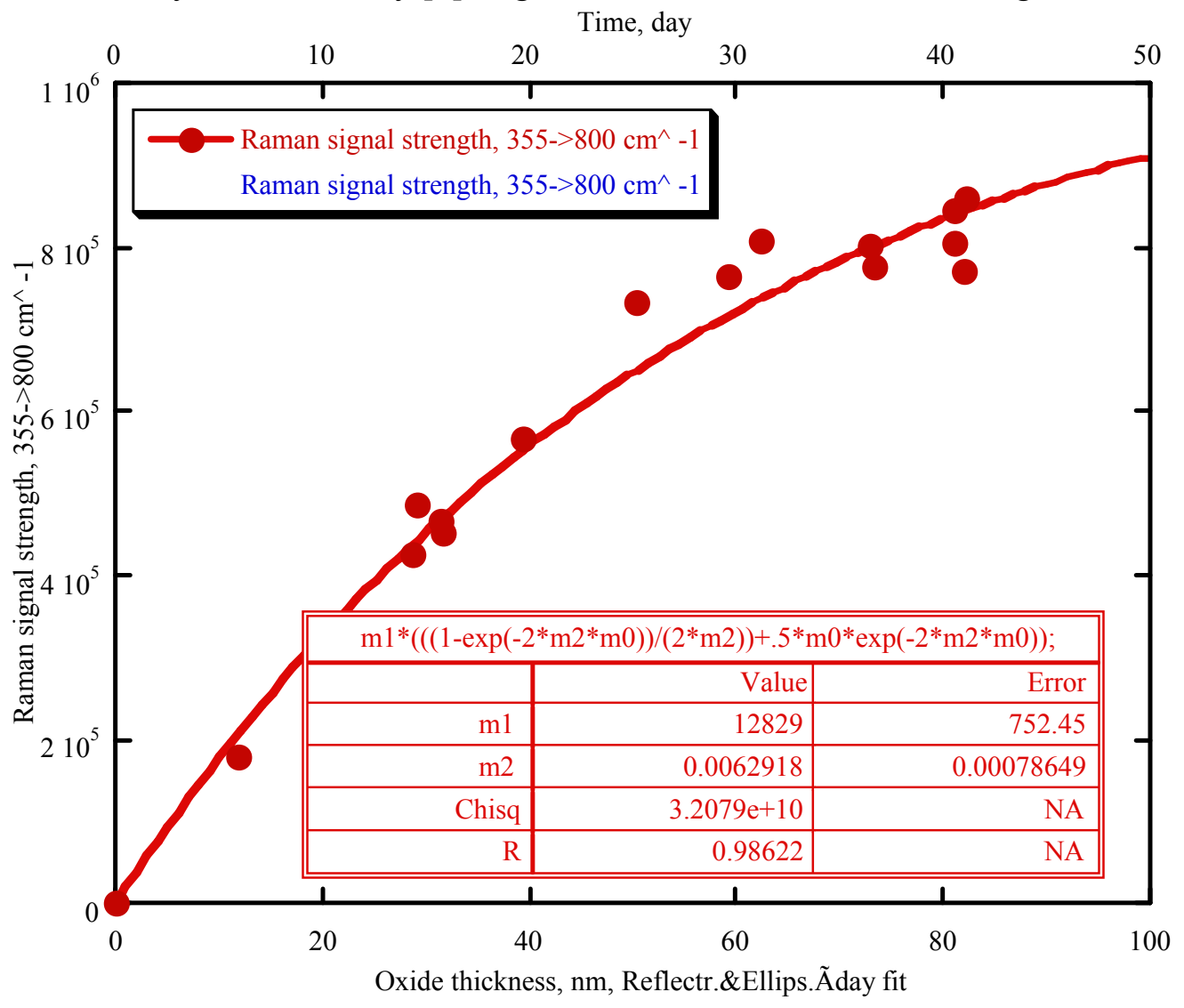

Figure 3. The observed Raman signal as a function of time (upper x-axis) and as a function of oxide thickness, and the model fit to the data.

The relationship between time and oxide thickness used in figure 3 was derived from ellipsometry and reflectrometry measurements of oxide growth on the same 
sample [1]. The oxide growth on uranium is proportional to the square root of time. The absorption coefficient $\alpha_{i}\left(=m 2\right.$ in the insert in figure 2) $\alpha_{1}=.00629 \mathrm{~nm}^{-1}$ $=4 \pi \mathrm{k} / \lambda$ (wavelength, $632 \mathrm{~nm}$ ), hence $->\mathrm{k}=.317$, a value of the extinction coefficient close to the value observed in the reflectrometry measurements [1].

\section{Detection of local impurity content or inclusions.}

A different uranium sample was analyzed and found to have visible carbide inclusions (figure 4 a). Spectra (figure 4 b) were taken on the carbide inclusion (points 0 and 1 ) and on different points ( 2 to 8 ) on an adjacent grain. The Raman spectra show on points 2 to 8 in addition to the $\mathrm{UO}_{2}$ peaks at 445,575 and $1150 \mathrm{~cm}^{-1}$ strong peaks at 740 and 950 $\mathrm{cm}^{-1}$ while the shoulder at $\sim 640 \mathrm{~cm}^{-1}$ is missing. The peak at $740 \mathrm{~cm}^{-1}$ is observed in $\mathrm{U}_{3} \mathrm{O}_{8}$, but the peak at $950 \mathrm{~cm}^{-1}$ has not been observed in the literature, and hence is most likely associated with an unknown impurity. The carbide inclusion shows only small signals above the background at 575 and $950 \mathrm{~cm}^{-1}$, possibly indicating that the impurity is also present in the car bide. Point 2 (yellow line) shows a significant reduction in the $\mathrm{UO}_{2}$ peaks at 445 and $1150 \mathrm{~cm}^{-1}$ and hence a higher content of the constituents represented by the remaining peaks.
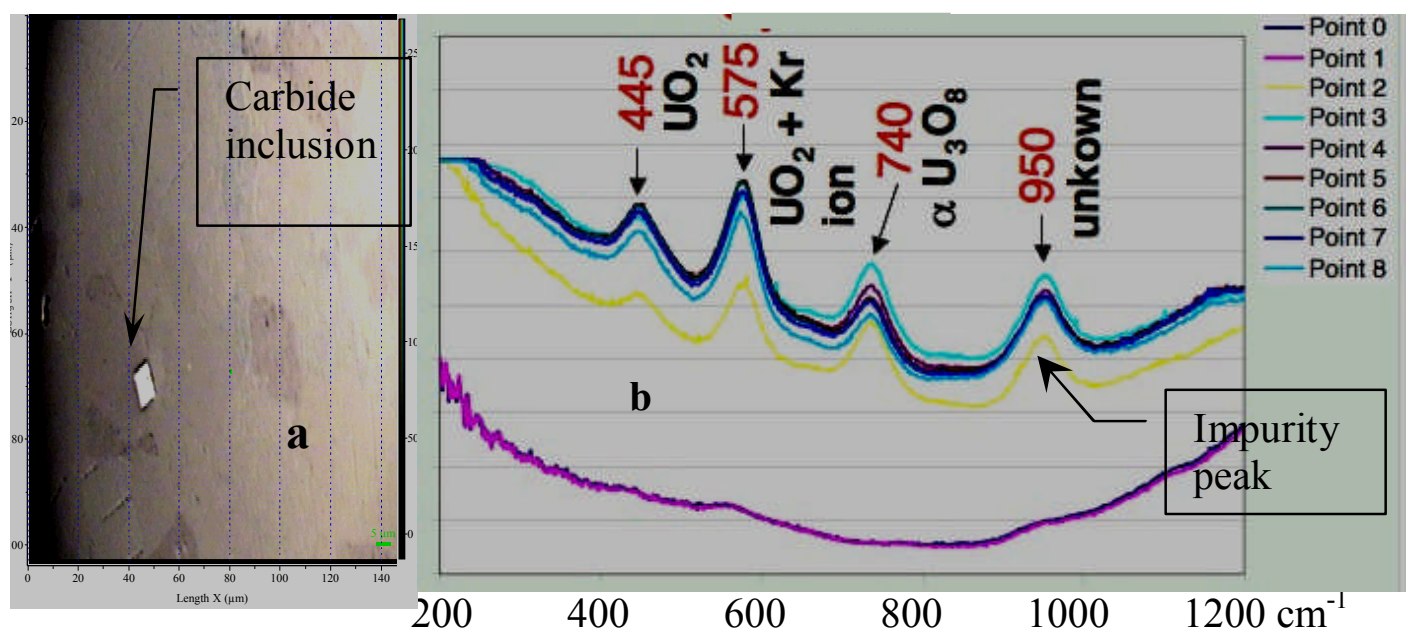

Figure 4. a) Micro-Raman microscope image of an uranium surface showing a carbide inclusion and several grains. b) Raman signal as a function of position. Points 0 and 1 are spectra on the carbide inclusion, points 2 to 8 are at different locations on a "grey" grain.

\section{CONCLUSIONS}

This work demonstrates that micro-Raman spectroscopy can be used to determine differences in local thickness of an uranium surface oxide layer. In addition, the local oxide moiety as well as impurity inclusions or impurity content can be determined. All these measurable factors may be useful in determining the causes of localized chemical attack, such as uranium hydriding. 


\section{ACKNOWLEDGMENTS}

This work was performed under the auspices of the U. S. Department of Energy by the University of California, Lawrence Livermore National Laboratory under Contract No. W-7405-Eng-48. The Seaborg Institute at the Lawrence Livermore Laboratory supported Niña Caculitan.

\section{REFERENCES}

[1] W. J. Siekhaus, in Actinides, Basic Science, Applications \& Technology, Mater. Res. Soc. Symp. Proc. Fall 2005, Boston, to be published.

[2] G. C. Allen, I. S. Butler, et al., Journal of Nuclear Materials 144(1-2), 17-19 (1987)

[3] P. R. Graves, Applied Spectroscopy 44(10), 1665-1667 (1990)

[4] M. L. Palacios, and S. H. Taylor, Applied Spectroscopy 54(9), 1372-1378 (2000).

[5] D. Manara and B. Renker, Journal of Nuclear Materials 321(2-3): 233-237 (2003)

[6] J. Bloch, F. Simca, et al.. Journal of the Less-Common Metals 103(1), 163-171(1984)

[7] J. Glascott AWE, Aldermaston, Great Britain, private communication. 